\title{
Midlife development of type 2 diabetes and hypertension in women by history of hypertensive disorders of pregnancy
}

\author{
Simon Timpka ${ }^{1,2^{*}}$ (D), Amanda Markovitz ${ }^{1,3}$, Tommy Schyman $^{4}$, Ingrid Mogren ${ }^{5}$, Abigail Fraser ${ }^{6,7,8}$, \\ Paul W. Franks ${ }^{2,3,9}$ and Janet W. Rich-Edwards ${ }^{1,3}$
}

\begin{abstract}
Background: Women with history of hypertensive disorders of pregnancy (HDP) are at increased risk of early onset cardiovascular disease and type 2 diabetes (T2D). We aimed to investigate the extent to which HDP is also associated with midlife development of T2D and hypertension above and beyond established risk factors.

Methods: We included parous women who attended population-based structured clinical visits at age 50 and 60 years in Sweden 1991-2013 ( $N=6587)$. Women with prior diabetes mellitus, stroke, or ischemic heart disease at age 50 years were excluded. Data on reproductive history were collected from registries. To study the association between history of HDP and the between-visits development of T2D, hypertension, and clinical risk factors of cardiometabolic disease (body mass index (BMI), blood pressure, and total cholesterol), we utilized multivariable adjusted regression models (logistic, log binomial, and linear regression, respectively). Models included data on outcome risk factors at age 50 years, e.g. BMl, $75 \mathrm{~g} 2 \mathrm{~h}$ oral glucose tolerance test result, and mean arterial pressure, respectively.

Results: Between ages 50 and 60 years, $5.8 \%$ of initially disease-free women developed T2D and 31.6\% developed hypertension. History of HDP was associated with increased risk of developing T2D between age 50 and 60 years even when adjusting for risk factors, including BMI, at age 50 years (odds ratio (OR) 1.96, 95\% confidence interval (CI) 1.29-2.98). By contrast, the higher risk of developing hypertension observed in women with history of HDP (relative risk (RR) 1.47, 95\% Cl 1.22-1.78) was attenuated when adjusted for risk factors (RR 1.09, 95\% Cl 0.94-1.25). Participants with a history of HDP had higher mean BMI and blood pressure at age 50 years, with levels roughly corresponding to those observed at age 60 years in unaffected women.
\end{abstract}

Conclusions: Women with history of HDP are not only at higher risk of cardiometabolic disease during their reproductive years, but HDP is also associated with midlife T2D development above and beyond established risk factors.

Keywords: Hypertensive disorders of pregnancy, Preeclampsia, Gestational hypertension, Epidemiology, Type 2 diabetes, Hypertension

\section{Background}

Hypertensive disorders of pregnancy (HDP: preeclampsia and gestational hypertension) are potentially lifethreatening obstetric complications that affect $3-10 \%$ of all pregnancies [1]. Women with a history of HDP also

\footnotetext{
*Correspondence: simon.timpka@med.lu.se

${ }^{2}$ Genetic and Molecular Epidemiology Unit, Lund University Diabetes

Centre, Clinical Sciences Malmö, Lund University, Malmö, Sweden

Full list of author information is available at the end of the article
}

develop hypertension at a younger age, [2-4] and are at twice the risk of developing type 2 diabetes (T2D) $[5,6]$ and cardiovascular disease (CVD) post-pregnancy [710]. This has led to calls for HDP history to be used for identifying women with an adverse risk factor profile at a young age $[11,12]$. However, less is known about the clinical relevance of information on HDP history for cardiometabolic disease prevention in middle age, especially when concomitantly considered with cardiometabolic risk factors.

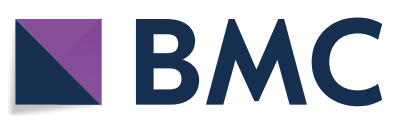

(c) The Author(s) 2018. This article is distributed under the terms of the Creative Commons Attribution 4.0 International License (http://creativecommons.org/licenses/by/4.0/), which permits unrestricted use, distribution, and reproduction in any medium, provided you give appropriate credit to the original author(s) and the source, provide a link to the Creative Commons license, and indicate if changes were made. The Creative Commons Public Domain Dedication waiver (http://creativecommons.org/ publicdomain/zero/1.0/) applies to the data made available in this article, unless otherwise stated. 
In this study we were interested in the association between HDP history and the development of T2D and hypertension in a cohort of women with clinical visits at age 50 and 60 years. To mimic a primary prevention setting, we sought to estimate associations independently of any cardiometabolic deterioration already clinically apparent at age 50 years, and included predictors of later cardiometabolic health in our models. To further understand the clinical relevance of the association between history of HDP and cardiometabolic risk factors [including blood pressure and body mass index (BMI)] in midlife, we also investigated these associations at age 50 years, the respective change in any association by age 60 years, and compared the associations with those attributable to the 10 years of older age between visits. Our primary hypothesis was that in women initially free of severe cardiovascular disease, history of HDP is positively associated with developing T2D and hypertension between age 50 and 60 years also when accounting for conventional predictors of cardiometabolic deterioration measurable at age 50 years.

\section{Methods}

In this prospective cohort study, we utilized a combination of clinical data, collected in a standardized population-based setting in northern Sweden, and comprehensive registry resources on reproductive history including pregnancy complications. Data on hospitalizations and cause of death were collected from the Swedish in-patient and Cause of Death Registry, respectively. Data on place of residence and educational level were collected from Statistics Sweden (Örebro, Sweden).

\section{Study sample identification}

We included parous women who attended populationbased structured clinical visits in primary care (The Västerbotten Intervention Program) at age 50, and again 10 years later, both visits occurring between 1991 and 2013 in northern Sweden (Fig. 1). Of 11,244 potentially eligible parous women, we included 8720 women with full reproductive history. This was defined as living in the geographical area covered by the regional pregnancy register in 1968, when data on place of residence for all participants were available. Women with known diabetes mellitus during pregnancy were excluded as these women are already known to have a very high risk of T2D and because we did not have data on pre-pregnancy diabetes status. The identification of the study sample is shown in Fig. 1. We excluded women with severe cardiovascular disease before the first visit at age 50 years (stroke, transient ischemic attack, myocardial infarction, or angina) according to in-patient ICD codes (version 9 or 10) or self-report, including anti-angina medication. As there was a small proportion of missing data in our final sample $(<5 \%$ missing any variable), we performed complete case analyses for each outcome.

\section{Data on reproductive history}

Data on reproductive history, including HDP (hypertension in pregnancy, preeclampsia, and eclampsia), were collected from regional to national delivery registries. In short, we utilized a local birth registry for the period 1955-1972 [13] (see Additional file 1) and the national Swedish Medical Birth Registry for the period from 1973 onwards. We utilized ICD codes to identify women with a reported diagnosis of HDP or diabetes mellitus during pregnancy (see Additional file 1 for ICD codes).

\section{Cardiometabolic measurements at age $\mathbf{5 0}$ years visit and at the 10-year follow-up}

All women aged 50 and 60 years living in the county of Västerbotten in northern Sweden have since 1991 been invited to undergo standardized health assessments, focused on cardiometabolic health prevention, at their primary care centers $[14,15]$. Study visits are conducted by a nurse and, for participants who are not already diagnosed with diabetes mellitus, typically include a $75 \mathrm{~g}$ $2 \mathrm{~h}$ oral glucose tolerance test (OGTT). For the purpose of this study, diabetes mellitus was defined either as (I) self-report of previous diagnosis (II) fasting capillary plasma glucose ( $\geq 7.0 \mathrm{mmol} / \mathrm{l})$ (III) $2 \mathrm{~h}$ capillary plasma glucose $>12.1$ (IV) currently taking anti-diabetic drugs or $(\mathrm{V})$ reporting lifestyle treatment for diabetes. Total serum cholesterol was analyzed locally at each primary health care center using a Reflotron bench analyzer until August 2009 and then onwards at the central clinical chemistry lab at Umeå University Hospital. From 1991 to August 2009, blood pressure was measured with a sphygmomanometer with the participants in a horizontal position after a five min rest. From September 2009 onwards, blood pressure was measured with the participants in a seated position. As the large majority of the blood pressure measurements in this study was performed prior to 2009 , we converted all measurements taken with the participant in a seated position to horizontal values by using age-specific formulae [16]. We defined hypertension as either (I) systolic blood pressure (SBP) $\geq 140 \mathrm{mmHg}$ (II) diastolic blood pressure (DBP) $\geq 90 \mathrm{mmHg}$ or (III) self-report use of anti-hypertensive drugs. Mean arterial pressure was calculated as $\mathrm{DBP}+[(\mathrm{SBP}-\mathrm{DBP}) / 3]$. Participant body weight and height were measured by a nurse and BMI was calculated as (weight in $\mathrm{kg}$ )/(height in $\mathrm{m})^{2}$. Smoking habits, family history of diabetes mellitus, and family history of CVD were collected via self-administered questionnaires. 


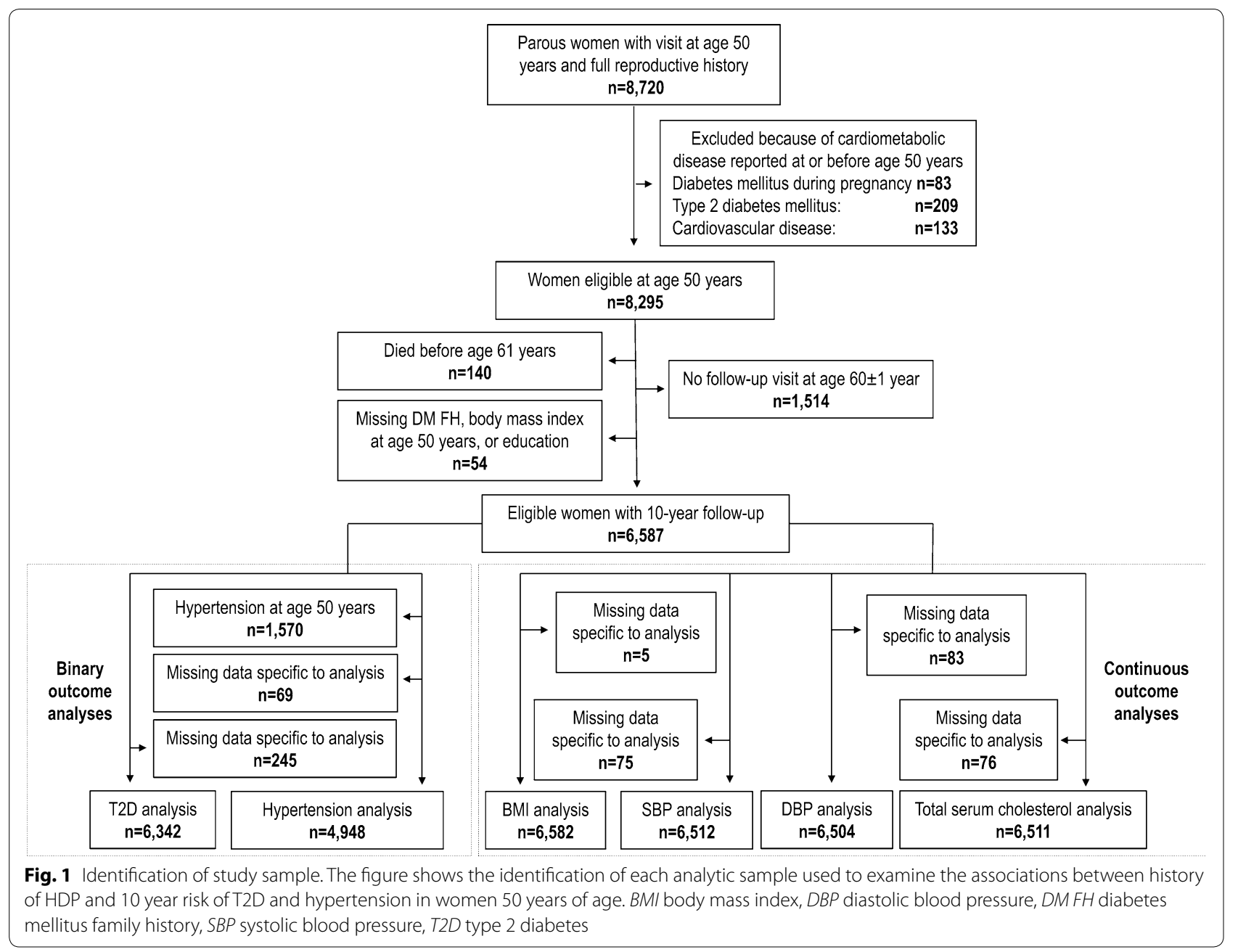

As previously recommended, [17] for these analyses we added a constant to the clinical measurement to compensate for anti-hypertensive or lipid-lowering medication, respectively. When analyzing continuous blood pressure, we added a standard $15 \mathrm{mmHg}$ to SBP and $10 \mathrm{mmHg}$ to DBP if participants reported anti-hypertensive drug use [17]. When analyzing continuous serum cholesterol, we added $1.336 \mathrm{mmol} / \mathrm{l}$ for participants who reported use of lipid lowering drugs [18].

\section{Statistical analyses}

In the analyses of binary outcomes, we investigated the associations between history of HDP and 10-year risk of developing of T2D and hypertension between 50 and 60 years of age. We utilized logistic regression for T2D and, as we anticipated a high prevalence of hypertension at follow-up, we utilized log binomial regression to directly obtain a risk ratio and $95 \%$ confidence interval (CI) for hypertension. In Model I, we included HDP history. In Model II, we adjusted for family history of
CVD and T2D, BMI, smoking, education level, and year of birth. In the main model (Model III), we further included a measure of already accumulated risk of the outcome at age 50 years (capillary glucose at $2 \mathrm{~h}$ post OGTT for T2D and mean arterial pressure at age 50 years for the hypertension analyses, respectively).

In the analyses of continuous outcomes, we investigated the association between history of HDP and several cardiometabolic risk factors (BMI, SBP, DBP, log total serum cholesterol) at ages 50 and 60 years and whether these associations changed with age. To do so we used linear mixed models with fixed effects for the betweenparticipant variation. We estimated $95 \%$ CIs and calculated complementary p-values. In Model I, we included HDP history, age at clinical visit, and an interaction term between the HDP history and age. In Model II, we adjusted for family history of CVD and family history of diabetes mellitus. In the main model (Model III), we further included education level, smoking, year of birth, BMI (when BMI was not the dependent variable), as well 
as interaction terms for age and smoking and age and BMI (when BMI was not the dependent variable). Participants eligible for these analyses had no missing data at either of their visits, resulting in 6504-6582 participants contributing data (Fig. 1).

As an additional analysis we wanted to replicate previous findings on the association between history of HDP and post-pregnancy development of T2D and hypertension. To do so, we used regression models, as described above for T2D and hypertension, but did not exclude women based on their cardiometabolic status at age 50 years. Instead, we utilized the data from the initial age 50 years clinical visit as outcome data. In addition to a crude analysis, we analyzed models adjusted for education level and family history. All analyses were performed using SAS 9.4.

\section{Results}

Table 1 shows the participant characteristics stratified by history of HDP. In total, 285 (4.3\%) women had at least one pregnancy complicated by HDP and resulting in a birth. Whereas women with a history of HDP had similar educational level as women not affected, they had markedly higher blood pressure at ages 50 and 60 years. During the 10 years of follow-up from age 50 years, 385 (5.8\%) participants developed T2D of whom 36 women $(9.4 \%)$ had a history of HDP. Of the 4958 normotensive participants at age 50 years, including 10 participants with missing data and not included in the regression model, 1568 (31.6\%) had developed hypertension 10 years later.

\section{Confirmation of the association between history of hypertensive disorders of pregnancy and cardiometabolic disease at age $\mathbf{5 0}$ years}

The analyses focusing on cardiometabolic disease development between pregnancy and age 50 years included 8601 women in the T2D analysis and 8476 women in the hypertension analysis. In these analyses, history of HDP was associated with an increased odds ratio (OR) of T2D in both the crude (OR 3.26, 95\% CI 2.13-4.99) and adjusted analysis (OR 3.13, 95\% CI 2.04-4.80). Likewise, HDP history in any pregnancy was associated with an increased risk of hypertension

Table 1 Study sample characteristics by history of HDP

\begin{tabular}{|c|c|c|c|c|}
\hline & \multicolumn{2}{|c|}{ No history of HDP } & \multicolumn{2}{|l|}{ HDP history } \\
\hline & & Missing data, $\mathbf{N}$ & & Missing data, $\mathbf{N}$ \\
\hline N participants (\%) & $6302(95.7)$ & - & $285(4.3)$ & - \\
\hline Age at age 50 visit, years mean \pm SD & $50.1 \pm 0.3$ & - & $50.1 \pm 0.3$ & - \\
\hline Age at age 60 visit, years mean $\pm S D$ & $60.0 \pm 0.2$ & - & $60.0 \pm 0.2$ & - \\
\hline Family history of CVD, N (\%) & $1787(28.4)$ & - & $92(32.3)$ & - \\
\hline Family history of diabetes, N (\%) & $1968(31.2)$ & - & $99(34.7)$ & - \\
\hline MAP at 50 years, $\mathrm{mmHg}$ mean $\pm \mathrm{SD}$ & $95 \pm 13$ & 68 & $106 \pm 14$ & 4 \\
\hline $\mathrm{SBP}$ at 50 years, $\mathrm{mmHg}$ mean $\pm \mathrm{SD}$ & $127 \pm 19$ & 61 & $141 \pm 20$ & 4 \\
\hline $\mathrm{SBP}$ at 60 years, $\mathrm{mmHg}$ mean $\pm \mathrm{SD}$ & $136 \pm 20$ & 5 & $146 \pm 19$ & - \\
\hline DBP at 50 years, $\mathrm{mmHg}$ mean $\pm \mathrm{SD}$ & $79 \pm 11$ & 67 & $88 \pm 13$ & 4 \\
\hline DBP at 60 years, $\mathrm{mmHg}$ mean $\pm \mathrm{SD}$ & $82 \pm 11$ & 7 & $87 \pm 11$ & - \\
\hline $\mathrm{BMl}$ at 50 years, $\mathrm{kg} / \mathrm{m}^{2}$ mean $\pm \mathrm{SD}$ & $25.3 \pm 4.0$ & - & $26.5 \pm 4.5$ & - \\
\hline $\mathrm{BMl}$ at 60 years, $\mathrm{kg} / \mathrm{m}^{2}$ mean $\pm \mathrm{SD}$ & $26.4 \pm 4.5$ & 5 & $27.4 \pm 4.8$ & - \\
\hline $2 \mathrm{~h}$ glucose post-OGTT at age 50 years, $\mathrm{mmol} / \mathrm{I}$ mean $\pm \mathrm{SD}$ & $6.78 \pm 1.3$ & 233 & $6.92 \pm 1.4$ & 11 \\
\hline Education level, N (\%) & & - & & - \\
\hline Elementary school or less & $1167(18.5)$ & & $56(19.7)^{*}$ & \\
\hline High school & $3390(53.8)$ & & $157(55.1)^{*}$ & \\
\hline College/University & $1745(27.7)$ & & $72(25.3)^{*}$ & \\
\hline Cholesterol age 50 years, mmol/I median (IQR) & $5.62(4.99 ; 6.35)$ & 59 & $5.83(5.10 ; 6.65)$ & 1 \\
\hline Cholesterol age 60 years, mmol/l median (IQR) & $5.95(5.30 ; 6.64)$ & 11 & $6.00(5.38 ; 6.76)$ & 1 \\
\hline Smoking age 50 years, N (\%) & $1449(23.0)$ & - & $54(19.0)$ & - \\
\hline Smoking age 60 years, N (\%) & $911(14.5)$ & - & $32(11.2)$ & - \\
\hline
\end{tabular}

Dashes in columns are markers of no missing data in the study sample

$B M I$ body mass index, DBP diastolic blood pressure, MAP mean arterial blood pressure, OGTT oral glucose tolerance test, SBP systolic blood pressure

* Percentage not adding up to $100 \%$ due to rounding 
at age 50 years (relative risk (RR) 2.27, 95\% CI 2.062.51 and 2.22 , 95\% CI 2.01-2.44, respectively).

\section{History of hypertension disorders of pregnancy and midlife development of cardiometabolic disease}

Table 2 shows history of HDP to be associated with incident T2D between age 50 and 60 years, even after adjusting for cardiometabolic health, including glucose response to OGTT, at age 50 years (OR 1.96, 95\% CI 1.29-2.98). History of HDP was associated with incident hypertension between age 50 and 60 years (crude RR 1.47, 95\% CI 1.22-1.78) but this association was abrogated in the model that adjusted for blood pressure and other risk factors at age 50 years (RR 1.09, 95\% CI 0.94-1.26).

\section{History of hypertensive disorders of pregnancy and cardiometabolic risk factor status at age $\mathbf{5 0}$ and 60 years}

Table 3 shows history of HDP to be associated with approximately one unit higher BMI at both age 50 and 60 years, as evidenced in the second column and the lack of interaction between age and HDP history in the sixth column. History of HDP was also associated with higher SBP and DBP and this difference at age 50 years (on the order of $12 \mathrm{mmHg}$ SBP and $8 \mathrm{mmHg}$ DBP) are greater or comparable to the age-related difference (roughly $10 \mathrm{mmHg}$ SBP and $4 \mathrm{mmHg}$ DBP) between visits at age 50 and 60 years in all women. However, the absolute effect size attributable to history of HDP was roughly $3 \mathrm{mmHg}$ lower at age 60 years for both DBP and SBP

\begin{tabular}{lccc}
$\begin{array}{l}\text { Table } 2 \text { HDP } \\
\text { and hypertension between age } \mathbf{5 0} \text { and } \mathbf{6 0} \text { years }\end{array}$ & $\begin{array}{c}\text { incident } \\
\text { type }\end{array}$ \\
\hline Model & OR of T2D $\left(\mathbf{9 5} \% \mathrm{Cl}^{\mathbf{a}}\right.$ & $\begin{array}{l}\mathbf{R R} \\
\text { of hypertension } \\
\mathbf{( 9 5 \% ~ C I})^{\mathbf{b}}\end{array}$ \\
\hline Model I & $2.35(1.61 ; 3.44)$ & $1.47(1.22 ; 1.78)$ \\
Model ÏI & $1.98(1.33 ; 2.95)$ & $1.30(1.10 ; 1.53)$ \\
Model III & $1.96(1.29 ; 2.98)$ & $1.09(0.94 ; 1.25)$ \\
\hline
\end{tabular}

Model I includes: history of HDP (yes or no)

Model II additionally includes: family history of diabetes mellitus (yes or no), family history of cardiovascular disease (yes or no), body mass index at age 50 years, education level ( 9 years or less, $10-12$ years, $>12$ years), smoking status at age 50 years (yes or no), and year of birth

Model III additionally includes: capillary glucose at $2 \mathrm{~h}$ following $75 \mathrm{~g}$ OGTT at age 50 years (for T2D) or mean arterial pressure at age 50 years (for hypertension)

$\mathrm{Cl}$ confidence interval, HDP hypertensive disorders of pregnancy, OR odds ratio $R R$ relative risk, T2D type 2 diabetes mellitus, OGTT oral glucose tolerance test

a Modelled with logistic regression

b Modelled with log binomial regression compared to age 50 years ( $\mathrm{p}$ for interaction $<0.05$ for all BP comparisons). Although history of HDP was associated with higher total serum cholesterol at both age 50 and 60 years, these associations were small compared to the age-related increase.

\section{Additional analyses}

When we compared the characteristics at age 50 years for women who did and did not attend the follow-up visit, there was no difference in educational level or proportion of women with history of HDP (Additional file 1: Table S1). However, women who did not attend the age 60 years visit were more likely to be smokers at age 50 years and had a tendency of worse mean OGTT result or being hypertensive at the initial visit. Women $(\mathrm{N}=2524)$ who were excluded due to missing reproductive history had similar prevalence of diabetes at age 50 years compared to the study sample (Additional file 1: Table S2). The excluded women had higher level of education and slightly lower blood pressure at age 50 years. However, the absolute difference in blood pressure was small compared to the estimate associated with having a history of HDP in the main sample.

\section{Discussion}

We found history of HDP to be positively associated with incident T2D in women between age 50 and 60 years even after adjustment for clinical risk factors at age 50 years, including OGTT result. By contrast, for hypertension this association was abrogated when we adjusted for risk factors, including MAP. Although the absolute difference in blood pressure was smaller by age 60 years, women with a history of HDP had higher mean BMI and blood pressure at both age 50 and 60 years. Their respective level at age 50 years roughly corresponded to those observed at age 60 years in unaffected women.

Hypertensive disorders of pregnancy as a predictor of T2D In our main analysis we have included women without T2D or CVD at age 50 years, controlled for their risk at 50 years, and followed them for 10 years. This approach is novel in the field and, by and large, it mimics a primary prevention setting in which women not yet diagnosed with severe cardiometabolic disease seek advice on prevention and disease risk from their health care provider. To replicate the decision process in the primary care setting, we include known predictors of these outcomes likely to be available to the primary care clinician, to investigate the additional value of HDP history as a clinical predictor above and beyond what is already considered by practitioners. The results suggest that 
Table 3 The association of HDP history and CVD risk factors at age 50, the change in CVD risk factors from age 50 to age 60 years, and the interaction between HDP history and age

\begin{tabular}{|c|c|c|c|c|c|c|c|}
\hline & $\begin{array}{l}\text { Age 50, } \\
\text { no HDP } \\
\text { history }\end{array}$ & $\begin{array}{l}\text { Mean difference } \\
\text { at age } 50 \text { years } \\
\text { in women with history } \\
\text { of HDP }(95 \% \mathrm{Cl})\end{array}$ & $\mathrm{p}$, history of HDP & $\begin{array}{l}\text { Mean difference, age } \\
60 \text { vs. } 50 \text { years ( } 95 \% \\
\text { Cl) }\end{array}$ & $p$, age & $\begin{array}{l}\text { Interaction, history } \\
\text { of HDP and age } \\
60 \text { years }(95 \% \mathrm{Cl})^{c}\end{array}$ & $p$, interaction \\
\hline \multicolumn{8}{|l|}{$\mathrm{BMI}, \mathrm{kg} / \mathrm{m}^{2}$} \\
\hline Model I & Reference & $1.16(0.66 ; 1.66)$ & $<0.001$ & $1.12(1.06 ; 1.17)$ & $<0.001$ & $-0.15(-0.42 ; 0.12)$ & 0.27 \\
\hline Model II & Reference & $1.13(0.63 ; 1.63)$ & $<0.001$ & $1.12(1.06 ; 1.17)$ & $<0.001$ & $-0.15(-0.42 ; 0.12)$ & 0.27 \\
\hline Model III & Reference & $1.09(0.59 ; 1.59)$ & $<0.001$ & $1.06(1.00 ; 1.12)$ & $<0.001$ & $-0.15(-0.42 ; 0.12)$ & 0.27 \\
\hline \multicolumn{8}{|l|}{$\mathrm{SBP}, \mathrm{mmHg}$} \\
\hline Model I & Reference & $13.5(11.2 ; 15.8)$ & $<0.001$ & $8.28(7.85 ; 8.72)$ & $<0.001$ & $-2.84(-4.94 ;-0.73)$ & 0.01 \\
\hline Model II & Reference & $13.3(11.1 ; 15.6)$ & $<0.001$ & $8.28(7.85 ; 8.72)$ & $<0.001$ & $-2.84(-4.94 ;-0.73)$ & 0.01 \\
\hline Model III & Reference & $11.5(9.32 ; 13.7)$ & $<0.001$ & $10.2(7.44 ; 12.9)$ & $<0.001$ & $-2.41(-4.49 ;-0.33)$ & 0.02 \\
\hline \multicolumn{8}{|l|}{$\mathrm{DBP}, \mathrm{mmHg}$} \\
\hline Model I & Reference & $8.58(7.23 ; 9.93)$ & $<0.001$ & $2.46(2.20 ; 2.73)$ & $<0.001$ & $-3.15(-4.42 ;-1.89)$ & $<0.001$ \\
\hline Model II & Reference & $8.50(7.15 ; 9.85)$ & $<0.001$ & $2.46(2.20 ; 2.73)$ & $<0.001$ & $-3.15(-4.42 ;-1.89)$ & $<0.001$ \\
\hline Model III & Reference & $7.55(6.25 ; 8.86)$ & $<0.001$ & $4.06(2.42 ; 5.71)$ & $<0.001$ & $-2.91(-4.18 ;-1.65)$ & $<0.001$ \\
\hline \multicolumn{8}{|c|}{ Total serum cholesterol, \% ${ }^{\mathrm{a}}$} \\
\hline Model I & Reference & $3.9(1.4 ; 6.4)$ & 0.002 & $5.1(4.5 ; 5.7)$ & $<0.001$ & $-1.9(-4.7 ; 1.0)$ & 0.20 \\
\hline Model II & Reference & $3.8(1.3 ; 6.3)$ & 0.003 & $5.1(4.5 ; 5.7)$ & $<0.001$ & $-1.9(-4.7 ; 1.0)$ & 0.20 \\
\hline Model III & Reference & $3.5(1.0 ; 6.0)$ & 0.007 & $16.8(13.1 ; 20.5)$ & $<0.001$ & $-1.5(-4.3 ; 1.4)$ & 0.30 \\
\hline
\end{tabular}

Model I includes: history of HDP (yes or no), age at visit (50 or 60 years), interaction term between HDP and age at visit

Model II additionally includes: family history of diabetes mellitus (yes/no), family history of cardiovascular disease (yes or no)

Model III additionally adjusts for: smoking (yes or no), interaction term between age and smoking, education level (9 years or less, 10-12 years, >12 years), year of birth, BMI (not in model with BMI as outcome), interaction between age and BMI (not in model with BMI as outcome)

$B M I$ body mass index, $C l$ confidence interval, $C V D$ cardiovascular disease, DBP diastolic blood pressure, HDP hypertensive disorders of pregnancy, OGTT oral glucose tolerance test, SBP systolic blood pressure

a For cholesterol the results are presented as difference in percentage as the outcome is log transformed

b The effect estimate of 10 years age increase from age 50 years is shown for comparison with the effect estimate of HDP history at age 50 years

c Column shows the difference in associations with HDP history at age 60 years compared to age 50 years

information on history of HDP may be clinically useful for the prediction of midlife T2D development in women. The strong link between HDP history and metabolic function is supported by a previous study in which post-pregnancy obesity modified the association between history of HDP and hypertension [19]. When we investigated the relative risk of disease by HDP history at age 50 years, we in this study also confirm previous results suggesting women with history of HDP have increased risk of T2D and hypertension during the decades following pregnancy $[4,8]$. Sattar et al. suggested that pregnancy complications constitute potential susceptibility to future cardiometabolic disease [12] and our results suggest that history of HDP actually has potential as a clinical predictor of T2D in middle age. This susceptibility could potentially be mediated through a more adverse vascular, inflammatory and/or insulin resistant [20] predisposition that is tentatively revealed during pregnancy.

Fraser et al. reported that women with either a history of preeclampsia or gestational hypertension had worse risk factor profile and higher calculated CVD risk at mean age 48 years [21]. In several studies, history of HDP has also been reported to be associated with increased risk of hypertension post-pregnancy $[2,22]$. Our results suggest that history of HDP is associated with hypertension development midlife, but that this association is largely attenuated when blood pressure at the beginning of the 10-year interval is accounted for. Drost et al. reported on the longitudinal changes of cardiometabolic risk factors in middle age by HDP history [23]. In their analysis, history of HDP was associated with higher blood pressure but compared to this study the effect estimates were smaller. However, the prevalence of history of HDP in the study was noticeably high at $20 \%$. Our results also supports that women with history of HDP have higher BMI compared to other parous women, [24] but the absolute difference did not increase during midlife.

Several studies suggest an association also between maternal HDP and worse offspring metabolic health later in life $[25,26]$. However, the extent to which this association can translate into improved prediction in adulthood above and beyond established determinants is unknown. 


\section{Limitations}

By combining population-based clinically collected data with registry resources, we have assembled a large sample with objectively measured outcome data and complete reproductive history. However, the study also has potential limitations. We report a loss to follow-up of $20 \%$ at the age 60 years visit. While there was no difference in history of HDP status or education level by having attended the follow-up visit, the group that did not appeared to have a higher proportion of smokers and worse OGTT result. Regardless, our main study results depend on the assumption that loss of follow-up between study visit 1 and 2 does not induce major bias. As we mainly had outcome data registered at the follow-up visits at age 60 years, we did not utilize a survival model but analyzed the outcomes by that time point. We did not have full reproductive history on all women attending the age 50 years visit. As the reproductive data were mainly collected from a comprehensive regional register, it is likely that women missing reproductive history had immigrated to the region during or after their childbearing years. We do not think that it is plausible that the presented associations would vary greatly (i.e. presence of an interaction) between women who have delivered any children outside the counties covered by the register compared to those who have not. Still, additional studies in samples of other populations are needed to confirm the novel results we present. Of note is also that GDM was yet to be established as a distinct diagnostic entity in the 1950-1960s, and we do not have data on pre-pregnancy diagnoses. Thus, we cannot separate GDM from diabetes mellitus present prior to pregnancy. However, women with GDM or diabetes mellitus are excluded from the analytical sample in the main analysis. Similarly, we are not able to exclude women with hypertension prior to pregnancy. The HDP diagnoses are mostly collected from a regional register in which the specific accuracy has not been evaluated. However, data from Norway suggest that diagnoses on HDP set in the 1960s were of reasonable quality and provided some separation even between preeclampsia and gestational hypertension [27].

\section{Clinical relevance and future studies}

In contrast to the guidelines concerning GDM, which currently recommend regular screening for T2D, [28] the guidelines for follow-up after HDP are less specific [29]. Our results show that history of HDP is not only a post-pregnancy risk factor of $\mathrm{T} 2 \mathrm{D}$, but also a predictor of midlife T2D development even after adjusting for post-pregnancy metabolic status. Nonetheless, the clinical utility of history of HDP should also be investigated in less ethnically homogenous populations. As the awareness of the link between HDP history and later cardiometabolic disease is insufficient among physicians in the United States, [30, 31] efforts are needed to inform clinical practice regardless. By conveying the message of the worse cardiometabolic status associated with history of HDP through comparisons with age-related decline, [32] the communication of guidelines and their penetration to clinical practice might be facilitated.

\section{Conclusions}

In this study we found history of HDP to be associated with midlife T2D development in parous women initially free of severe cardiometabolic disease, even when adjusting for established predictors of cardiometabolic deterioration. This suggests that history of HDP as a clinical predictor of T2D development in middle aged women warrants further study. Women affected by HDP also had worse cardiovascular risk factor status at age 50 years, which roughly corresponded to 10 years of older age. In conclusion, our results suggest that information on previous HDP is not only relevant for the risk of cardiometabolic disease during the decades post-pregnancy, but might also be clinically useful to predict middle age T2D development above and beyond established risk factors.

\section{Additional file}

Additional file 1: Additional methods and results. Table S1: Descriptive comparison of cardiometabolic status at age 50 years between women alive at age 60 years with or without clinical visit. Table S2: Descriptive comparison of cardiometabolic status between women with and without full reproductive history at age 50 years.

Abbreviations

BMI: body mass index; CVD: cardiovascular disease; DBP: diastolic blood pressure; GDM: gestational diabetes mellitus; HDP: hypertensive disorders of pregnancy; OGTT: oral glucose tolerance test; OR: odds ratio; RR: relative risk; SBP: systolic blood pressure; T2D: type 2 diabetes.

\section{Authors' contributions}

Acquired funding (ST, JWRE, PWF, AF), collected data (ST, IM), statistical analysis (TS, ST), ST with input from all authors planned the analysis, drafted the manuscript (ST). All authors read and approved the final manuscript.

\section{Author details}

${ }^{1}$ Connors Center for Women's Health and Gender Biology, Brigham and Women's Hospital and Harvard Medical School, Boston, MA, USA. ${ }^{2}$ Genetic and Molecular Epidemiology Unit, Lund University Diabetes Centre, Clinical Sciences Malmö, Lund University, Malmö, Sweden. ${ }^{3}$ Harvard T.H. Chan School of Public Health, Boston, MA, USA. ${ }^{4}$ Forum South, Clinical Studies Sweden, Skåne University Hospital, Lund, Sweden. ${ }^{5}$ Department of Clinical Sciences, Obstetrics and Gynecology, Umeå University, Umeå, Sweden. ${ }^{6}$ Population Health Sciences, Bristol Medical School, University of Bristol, Bristol, UK. ${ }^{7}$ MRC Integrative Epidemiology Unit at the University of Bristol, University of Bristol, Bristol, UK. ${ }^{8} \mathrm{NIHR}$ Biomedical Research Centre, The University Hospitals Bristol NHS Foundation Trust and the University of Bristol, Bristol, UK. ${ }^{9}$ Department of Public Health and Clinical Medicine, Umeå University, Umeå, Sweden. 


\section{Acknowledgements}

The authors would like to thank Dr. Azra Kurbasic (Genetic and Molecular Epidemiology Unit, Lund University, Sweden) for the initial data management and all participants in the Västerbotten Intervention Program.

\section{Competing interests}

The authors declare that they have no competing interests.

\section{Availability of data and materials}

There is no publicly available data due to the regulation of access to registrybased healthcare data in Sweden.

\section{Consent for publication}

Not applicable.

\section{Ethics approval and consent to participate}

This registry-based study was approved by the ethical review board at Lund University, Lund, Sweden.

\section{Funding}

This work was supported by grants from the Swedish Research Council; Bundy Academy, Lund, Sweden; Folksam Research Foundation, Sweden; The Swedish Heart and Lung Association; Anna Lisa and Sven Erik Lundgren's Foundation, Sweden; and Hulda and E Conrad Mossfelt's Foundation, Sweden (all to ST). AF is funded by a UK Medical Research Council (MRC) fellowship (MR/ M009351/1) and works in a unit that receives infrastructure funding from the MRC (MC UU 12013/5). AM is supported by the American Heart Association (grant number 16PRE29690006). The funding bodies had no role in the design of the study or in the collection, analysis, and interpretation of data or in writing the manuscript.

\section{Publisher's Note}

Springer Nature remains neutral with regard to jurisdictional claims in published maps and institutional affiliations.

Received: 7 May 2018 Accepted: 23 Auqust 2018

Published online: 10 September 2018

\section{References}

1. Hutcheon JA, Lisonkova S, Joseph KS. Epidemiology of pre-eclampsia and the other hypertensive disorders of pregnancy. Best Pract Res Clin Obstet Gynaecol. 2011;25:391-403.

2. Männistö T, Mendola P, Vääräsmäki $M$, Järvelin $M-R$, Hartikainen $A-L$, Pouta $A$, et al. Elevated blood pressure in pregnancy and subsequent chronic disease risk. Circulation. 2013;127:681-90.

3. Magnussen EB, Vatten LJ, Smith GD, Romundstad PR. Hypertensive disorders in pregnancy and subsequently measured cardiovascular risk factors. Obstet Gynecol. 2009;114:961-70.

4. Heida KY, Franx A, van Rijn BB, Eijkemans MJC, Boer JMA, Verschuren MWM, et al. Earlier age of onset of chronic hypertension and type 2 diabetes mellitus after a hypertensive disorder of pregnancy or gestational diabetes mellitus. Hypertension. 2015;66:1116-22.

5. Wu P, Kwok CS, Haththotuwa R, Kotronias RA, Babu A, Fryer AA, et al. Preeclampsia is associated with a twofold increase in diabetes: a systematic review and meta-analysis. Diabetologia. 2016;59:2518-26.

6. Wang Z, Wang Z, Wang L, Qiu M, Wang Y, Hou X, et al. Hypertensive disorders during pregnancy and risk of type 2 diabetes in later life: systematic review and meta-analysis. Endocrine. 2017;55:809-21.

7. Rich-Edwards JW, Fraser A, Lawlor DA, Catov JM. Pregnancy characteristics and women's future cardiovascular health: an underused opportunity to improve women's health? Epidemiol Rev. 2014;36:57-70

8. Lykke JA, Langhoff-Roos J, Sibai BM, Funai EF, Triche EW, Paidas MJ. Hypertensive pregnancy disorders and subsequent cardiovascular morbidity and type 2 diabetes mellitus in the mother. Hypertension. 2009;53:944-51
9. Nerenberg K, Daskalopoulou SS, Dasgupta K. Gestational diabetes and hypertensive disorders of pregnancy as vascular risk signals: an overview and grading of the evidence. Can J Cardiol. 2014:30:765-73.

10. Goueslard K, Cottenet J, Mariet A-S, Giroud M, Cottin Y, Petit J-M, et al. Early cardiovascular events in women with a history of gestational diabetes mellitus. Cardiovasc Diabetol. 2016;15:15

11. Catov JM, Bairey-Merz N, Rich-Edwards J. Cardiovascular health during pregnancy: future health implications for mothers. Curr Epidemiol Rep. 2017:4:232-8.

12. Sattar N, Greer IA. Pregnancy complications and maternal cardiovascular risk: opportunities for intervention and screening? BMJ. 2002;325:157-60.

13. Mogren I, Hogberg U, Winkvist A, Stenlund H. Familial occurrence of preeclampsia. Epidemiology. 1999;10:518-22.

14. Norberg M, Wall S, Boman K, Weinehall L. The Vasterbotten Intervention Programme: background, design and implications. Glob Health Action. 2010. https://doi.org/10.3402/gha.v3i0.4643.

15. Hallmans G, Agren A, Johansson G, Johansson A, Stegmayr B, Jansson J-H, et al. Cardiovascular disease and diabetes in the Northern Sweden Health and Disease Study Cohort-evaluation of risk factors and their interactions. Scand J Public Health. 2003:61:18-24.

16. Ng N, Carlberg B, Weinehall L, Norberg M. Trends of blood pressure levels and management in Västerbotten County, Sweden, during 1990-2010. Glob Health Action. 2012. https://doi.org/10.3402/gha.v5i0.18195.

17. Tobin MD, Sheehan NA, Scurrah KJ, Burton PR. Adjusting for treatment effects in studies of quantitative traits: antihypertensive therapy and systolic blood pressure. Stat Med. 2005;24:2911-35.

18. Wu J, Province MA, Coon H, Hunt SC, Eckfeldt JH, Arnett DK, et al. An investigation of the effects of lipid-lowering medications: genome-wide linkage analysis of lipids in the HyperGEN study. BMC Genet. 2007:8:60.

19. Timpka S, Stuart JJ, Tanz LJ, Rimm EB, Franks PW, Rich-Edwards JW. Lifestyle in progression from hypertensive disorders of pregnancy to chronic hypertension in Nurses' Health Study II: observational cohort study. BMJ. 2017;358:3024.

20. Sung K-C, Park H-Y, Kim M-J, Reaven G. Metabolic markers associated with insulin resistance predict type 2 diabetes in Koreans with normal blood pressure or prehypertension. Cardiovasc Diabetol. 2016;15:47.

21. Fraser A, Nelson SM, Macdonald-Wallis C, Cherry L, Butler E, Sattar N, et al. Associations of pregnancy complications with calculated cardiovascular disease risk and cardiovascular risk factors in middle age: the Avon Longitudinal Study of Parents and Children. Circulation. 2012;125:1367-80.

22. Behrens I, Basit S, Melbye M, Lykke JA, Wohlfahrt J, Bundgaard H, et al. Risk of post-pregnancy hypertension in women with a history of hypertensive disorders of pregnancy: nationwide cohort study. BMJ. 2017;358:j3078.

23. Drost J, van der Schouw Y, Maas A, Verschuren W. Longitudinal analysis of cardiovascular risk parameters in women with a history of hypertensive pregnancy disorders: the Doetinchem Cohort Study. BJOG Int J Obstet Gynaecol. 2013;120:1333-9.

24. Callaway LK, McIntyre HD, O'Callaghan M, Williams GM, Najman JM, Lawlor DA. The association of hypertensive disorders of pregnancy with weight gain over the subsequent 21 years: findings from a prospective cohort study. Am J Epidemiol. 2007:166:421-8.

25. Thoulass JC, Robertson L, Denadai L, Black C, Crilly M, Iversen L, et al. Hypertensive disorders of pregnancy and adult offspring cardiometabolic outcomes: a systematic review of the literature and meta-analysis. J Epidemiol Community Health. 2016;70:414-22.

26. Kajantie E, Osmond C, Eriksson JG. Gestational hypertension is associated with increased risk of type 2 diabetes in adult offspring: the Helsinki Birth Cohort Study. Am J Obstet Gynecol. 2017;216:281e1.

27. Thomsen LCV, Klungsøyr K, Roten LT, Tappert C, Araya E, Bærheim G, et al. Validity of the diagnosis of pre-eclampsia in the Medical Birth Registry of Norway. Acta Obstet Gynecol Scand. 2013;92:943-50.

28. American Diabetes Association. 12. Management of Diabetes in Pregnancy. Diabetes Care. 2015;38(Supplement 1):S77-9.

29. American College of Obstetricians and Gynecologists. Task Force on hypertension in pregnancy. Hypertension in pregnancy. Report of the American College of Obstetricians and Gynecologists'Task Force on hypertension in pregnancy. Obstet Gynecol. 2013;122:1122-31. 
30. Young B, Hacker MR, Rana S. Physicians'knowledge of future vascular disease in women with preeclampsia. Hypertens Pregnancy. 2012;31:50-8.

31. Wilkins-Haug L, Celi A, Thomas A, Frolkis J, Seely EW. Recognition by women's health care providers of long-term cardiovascular disease risk after preeclampsia. Obstet Gynecol. 2015;125:1287-92.
32. D'Agostino RB, Vasan RS, Pencina MJ, Wolf PA, Cobain M, Massaro JM, et al. General cardiovascular risk profile for use in primary care the Framingham Heart Study. Circulation. 2008;117:743-53.
Ready to submit your research? Choose BMC and benefit from:

- fast, convenient online submission

- thorough peer review by experienced researchers in your field

- rapid publication on acceptance

- support for research data, including large and complex data types

- gold Open Access which fosters wider collaboration and increased citations

- maximum visibility for your research: over $100 \mathrm{M}$ website views per year

At BMC, research is always in progress.

Learn more biomedcentral.com/submissions 